\title{
Bond load-slip behaviour of FRP bars in recycled-aggregate concrete
}

\author{
Ahmed Godat ${ }^{1,}$, Ebtesam Alghafri ${ }^{1}$, Noura AlTamimi ${ }^{1}$, Hamda Aljaberi ${ }^{1}$, and Shaima \\ Aldaweela ${ }^{1}$ \\ ${ }^{1}$ United Arab Emirates University, Civil and Environmental Engineering Department, Al-Ain, UAE
}

\begin{abstract}
This study presents an experimental program conducted to investigate the bond strength of FRP bars in recycled-aggregate concrete compared to the one in normal-aggregate concrete for the improved evaluation of results. The experimental program contains thirty six specimens tested using direct pull-out test. In this study, glass, carbon and basalt FRP bars are used with $12 \mathrm{~mm}$ diameter and bar bond lengths of $5 \mathrm{~d}$, where $\mathrm{d}$ is the bar diameter. The FRP bars are casted in different recycledaggregate concrete strengths of 30, 45 and $60 \mathrm{MPa}$. The behaviour of bars in normal-aggregate concrete strength of $30 \mathrm{MPa}$ is used as a benchmark and its behaviour is compared with the ones in the recycled-aggregate concrete. The impact of the concrete strength considered is identified based on the gain in the bond behaviour. The experimental results demonstrate the prospect of the recycled aggregates applied as an alternative to normal aggregates in the FRP reinforced concrete. In addition, the use of the recycled aggregate increases the bearing friction behaviour between the FRP bars and concrete.
\end{abstract}

\section{Introduction}

Sustainability has become one of the key parameters in the construction industry. Coarse aggregates constitute around $65 \%$ by weight of a non-air entrained concrete, while cement occupies only $16 \%$ to $18 \%$ of the concrete mix by weight. Replacing the aggregate content with available sustainable materials is more effective and beneficial for environmental protection and reduces the carbon foot print of concrete [1]. In addition, the use of the recycled aggregate is a way to reduce energy consumption and to maintain natural resources. The use of recycled aggregate in concrete members faces a popular argument concerning its high water consumption, which has a negative impact on its hardened concrete, and consequently, affects its compressive strength and properties.

Fibre reinforced polymer (FRP) bars such as glass, carbon and basalt have gained wide acceptance to replace steel bars as the internal reinforcement in concrete structures. FRP bars constitute a non-corrosive material which offers a promising solution to infrastructure decay since it prolongs their service life and reduces maintenance cost. Therefore, the FRP as a reinforced material for concrete members is required for durable and sustainable

\footnotetext{
* Corresponding author: Ahmed.Godat@uaeu.ac.ae
} 
constructions. One of the concepts of utmost importance in reinforced concrete members is the bond between the reinforcement and the concrete. Therefore, evaluating the bond of FRP bars in recycled aggregate is an essential requirement for reinforced concrete structures.

There are limited studies which were carried out to investigate the performance of the recycled-aggregate concrete in FRP reinforced members. Two research studies in the available literature addressed the bond behaviour between the recycled-aggregate concrete and GFRP bars [2] and BFRP bars [3]. The first study considered only GFRP bars with various ratios of recycled aggregates. The latter study investigated the bond strength results of BFRP bars in the recycled-aggregate concrete without benchmarking the bond strength results in the normal-aggregate concrete.

This study attempts to address the bond behaviour of FRP bars in the recycled-aggregate concrete using direct pull-out test. The findings from this research study are expected to increase the understanding of the bond behavior towards the recycled-aggregate concrete and its consideration in concrete design codes. As a result, designers will be able to avoid the bar pull-out failure and to develop the full capacity of recycled-aggregate concrete members reinforced with FRP bars.

\section{Experimental program}

\subsection{Material description}

The test specimens were prepared using $100 \%$ recycled aggregates imported from a local supplier, a demolition waste treatment and recovery plant. The particle size distribution was carried out and it was found similar to the one of the natural aggregate. The recycled aggregate had a size between 5-20 mm with an amount of adhered mortar on the recycled aggregate (Fig. 1a). In order to ensure the workability of the concrete mixes, the rate of water absorption of coarse aggregate was determined ahead of mix preparations. Following the ACI concrete standard [4], the rate of water absorption was $4.9 \%$ due to the presence of the adhered mortar.

The experimental program targeted three concrete strengths 30, 45, 60 MPa. The concrete strength was selected to be a parameter for study in order to investigate the FRP bond behaviour for high strength concrete. In addition, this selection is to follow the new engineering practice of using high-strength concrete with the FRP reinforcement. It should be noted that the concrete strength of $30 \mathrm{MPa}$ was obtained based on the BS 8500 [5]. For the concrete strength of $45 \mathrm{MPa}$, the concrete mix of BS 8500 [5] for $60 \mathrm{MPa}$ at 28 days was employed. The mix proportions proposed by the PCA [6] for high-performance concrete of $93 \mathrm{MPa}$ at 28 days were used to obtain the concrete strength of $60 \mathrm{MPa}$. In this study, the natural-aggregate concrete with the strength of $30 \mathrm{MPa}$ was taken as a benchmark for comparison. The constituent content for each concrete strength along with the measured slump is provided in Table 1 . The concrete compressive strength was determined using standard cubes of $100-\mathrm{mm}$ sides. Both concrete cubes and pull-out specimens were cured at the temperature of $23 \pm 2{ }^{\circ} \mathrm{C}$ and humidity of $95 \%$ for 28 days. The average strengths for the recycled-aggregate concrete were 34,47 and $63 \mathrm{MPa}$, whereas it was $37 \mathrm{MPa}$ for the regularaggregate concrete.

Pultruded glass, carbon and basalt FRP bars were utilized in this study with the nominal diameter of $12 \mathrm{~mm}$. The mechanical properties of the bars as reported by the manufacturer are presented in Table 2. The surface of CFRP bars was uniform with consistent sand coating (Fig. 1b), whereas the BFRP bar surface contained sand coating with shallow spiral indentations (Fig. 1c). The GFRP bars had a ribbed surface along the bar (Fig. 1d). The actual diameter of the BFRP and GFRP bars was larger than the nominal diameter by $2 \mathrm{~mm}$, and 4 mm for CFRP bars. 
Table 1. Concrete mix proportions and slump results

\begin{tabular}{|c|c|c|c|c|c|c|c|c|}
\hline $\begin{array}{c}\text { Mix } \\
\text { strength }\end{array}$ & $\begin{array}{c}\text { Cement } \\
\left(\mathbf{K g} / \mathbf{m}^{\mathbf{3}}\right)\end{array}$ & $\begin{array}{c}\text { Water } \\
\left(\mathbf{K g} / \mathbf{m}^{\mathbf{3}}\right)\end{array}$ & $\begin{array}{c}\text { Sand } \\
\left(\mathbf{K g} / \mathbf{m}^{\mathbf{3}}\right)\end{array}$ & $\begin{array}{c}\text { Aggregate } \\
\left(\mathbf{K g} / \mathbf{m}^{\mathbf{3}}\right)\end{array}$ & $\begin{array}{c}\text { Silica } \\
\mathbf{f u m e} \\
\left(\mathbf{K g} / \mathbf{m}^{\mathbf{3}}\right)\end{array}$ & $\begin{array}{c}\text { Water } \\
\mathbf{p l a s t i c i z e r} \\
\left(\mathbf{K g} / \mathbf{m}^{\mathbf{3}}\right)\end{array}$ & $\begin{array}{c}\text { Retarder } \\
\left(\mathbf{L} / \mathbf{m}^{\mathbf{3}}\right)\end{array}$ & $\begin{array}{c}\text { Slump } \\
\mathbf{( \mathbf { m m } )}\end{array}$ \\
\hline RC 30 & 448 & 203 & 610 & 1073 & - & - & - & 35 \\
\hline RC 45 & 600 & 210 & 517 & 1073 & - & - & - & 20 \\
\hline RC 60 & 500 & 135 & 700 & 1100 & 30 & 14 & 1.8 & 15 \\
\hline NC 30 & 448 & 203 & 610 & 1073 & - & - & - & 95 \\
\hline
\end{tabular}

Table 2. Mechanical properties of FRP bars

\begin{tabular}{|c|c|c|c|}
\hline Bar type & $\begin{array}{c}\text { Tensile strength } \\
\text { (MPa) }\end{array}$ & $\begin{array}{c}\text { Ultimate } \\
\text { strain (\%) }\end{array}$ & $\begin{array}{c}\text { Elastic modulus } \\
\text { (GPa) }\end{array}$ \\
\hline CFRP & 2800 & 1.8 & 155 \\
\hline GFRP & 1270 & 2.2 & 57 \\
\hline BFRP & 1017 & 2.2 & 48 \\
\hline
\end{tabular}

\subsection{Test specimens}

Cubic wooden moulds with $200 \mathrm{~mm}$-side were used to prepare the pull-out test specimens. FRP bars with 1,000 mm length were concentrically positioned in the mould. For all bars, the bond length is maintained as $5 \mathrm{~d}$, where $\mathrm{d}$ is the nominal bar diameter. Prior to concrete casting, plastic tubes wrapped the FRP bars to ensure the desired bond lengths (Fig. 1e). The bond length was located at the other end of the cube opposite to the pull-out direction. The other side of the FRP bar was inserted into a steel pipe casted with cement grout to avoid the crushing of the bar in the grip of the testing machine, as shown in Fig. 1(f). The vertical concentric position of the FRP bars after concrete casting was ensured by wooden plates fixed at the top end of the moulds, as depicted in Fig. 1(g-h).

The test matrix is listed in Table 3 . For each set of concrete strength, three specimens were prepared in order to ensure the reliability of the test results. The specimens were labelled as follows: the first term indicates the bar material type ( $\mathrm{C}$ for carbon, $\mathrm{B}$ for basalt and $\mathrm{G}$ for glass) followed by the bar diameter. The second term marks the concrete strength (RC for recycled concrete, and $\mathrm{NC}$ for normal concrete) along with the desired concrete strength. The third term denotes the order of the specimen in the test. For instance, B12-RC45-2 refers to the basalt FRP bar, in $45 \mathrm{MPa}$ recycled-aggregate concrete strength, and it is the second specimen in this group.

Table 3. Bond test matrix and test results

\begin{tabular}{|c|c|c|c|c|c|}
\hline Specimen & $\begin{array}{c}\text { Concrete } \\
\text { type }\end{array}$ & $\begin{array}{c}\text { Concrete } \\
\text { strength } \\
\text { (MPa) }\end{array}$ & $\begin{array}{c}\text { Maximum } \\
\text { bond load } \\
(\mathrm{kN})\end{array}$ & $\begin{array}{c}\text { Average } \\
\text { bond load } \\
(\mathrm{kN})\end{array}$ & Failure mode \\
\hline C12-RC30-1 & \multirow{6}{*}{$\begin{array}{l}\text { Recycled- } \\
\text { aggregate } \\
\text { concrete }\end{array}$} & \multirow{3}{*}{30} & 49.2 & \multirow{3}{*}{44.6} & Bar pull-out \\
\hline C12-RC30-2 & & & 36.6 & & Bar pull-out \\
\hline C12-RC30-3 & & & 48.4 & & Bar pull-out \\
\hline C12-RC45-1 & & \multirow{3}{*}{45} & 43.7 & \multirow{3}{*}{45.7} & Bar pull-out \\
\hline C12-RC45-2 & & & 46.0 & & Bar pull-out \\
\hline C12-RC45-3 & & & 47.3 & & Bar pull-out \\
\hline
\end{tabular}




\begin{tabular}{|c|c|c|c|c|c|}
\hline C12-RC60-1 & & \multirow{3}{*}{60} & 67.8 & \multirow{3}{*}{66.8} & Bar pull-out \\
\hline C12-RC60-2 & & & 65.6 & & Bar pull-out \\
\hline C12-RC30-3 & & & 67.0 & & Bar pull-out \\
\hline B12-RC30-1 & & \multirow{3}{*}{30} & 57.7 & \multirow{3}{*}{55.9} & Bar pull-out \\
\hline B12-RC30-2 & & & 57.0 & & Bar pull-out \\
\hline B12-RC30-3 & & & 52.9 & & Bar pull-out \\
\hline B12-RC45-1 & & \multirow{3}{*}{45} & 61.6 & \multirow{3}{*}{62.7} & Concrete splitting \\
\hline B12-RC45-2 & & & 62.9 & & Concrete splitting \\
\hline B12-RC45-3 & & & 63.7 & & Concrete splitting \\
\hline B12-RC60-1 & & \multirow{3}{*}{60} & 64.7 & \multirow{3}{*}{63.3} & Concrete splitting \\
\hline B12-RC60-2 & & & 63.7 & & Concrete splitting \\
\hline B12-RC60-3 & & & 61.6 & & Concrete splitting \\
\hline G12-RC30-1 & & \multirow{3}{*}{30} & 58.5 & \multirow{3}{*}{57.1} & Bar pull-out \\
\hline G12-RC30-2 & & & 51.8 & & Bar pull-out \\
\hline G12-RC30-3 & & & 61.0 & & Bar pull-out \\
\hline G12-RC45-1 & & \multirow{3}{*}{45} & 56.1 & \multirow{3}{*}{52.0} & Bar pull-out \\
\hline G12-RC45-2 & & & 49.0 & & Bar pull-out \\
\hline G12-RC45-3 & & & 51.0 & & Bar pull-out \\
\hline G12-RC60-3 & & \multirow{3}{*}{60} & 64.6 & \multirow{3}{*}{58.8} & Concrete splitting \\
\hline G12-RC60-3 & & & 59.2 & & Concrete splitting \\
\hline G12-RC60-3 & & & 52.6 & & Bar pull-out \\
\hline C12-NC30-1 & \multirow{9}{*}{$\begin{array}{l}\text { Normal- } \\
\text { aggregate } \\
\text { concrete }\end{array}$} & \multirow{9}{*}{30} & 48.6 & \multirow{3}{*}{45.5} & Bar pull-out \\
\hline C12-NC30-2 & & & 39.3 & & Bar pull-out \\
\hline C12-NC30-3 & & & 48.4 & & Bar pull-out \\
\hline B12-NC30-1 & & & 52.9 & \multirow{3}{*}{54.5} & Bar pull-out \\
\hline B12-NC30-2 & & & 53.5 & & Bar pull-out \\
\hline B12-NC30-3 & & & 57.0 & & Bar pull-out \\
\hline G12-NC30-1 & & & 49.5 & \multirow{3}{*}{45.9} & Bar pull-out \\
\hline G12-NC30-2 & & & 42.2 & & Bar pull-out \\
\hline G12-NC30-3 & & & 46.1 & & Bar pull-out \\
\hline
\end{tabular}

\subsection{Test setup and procedure}

Figures 1(i) and (j) show the test setup, instrumentation and geometry of the test specimens, respectively. All specimens were subjected to pull-out testing following the typical ASTM standard [7] procedure. The tests were carried out using a Baldwin testing machine in displacement control mode of $1.2 \mathrm{~mm} / \mathrm{min}$ in order to capture the post-peak behavior. The slip at the free end of the FRP bar was measured using a linear variable displacement transducer (LVDT). The applied pull-out load and the bar slippage were automatically recorded throughout the test. The test was stopped when no more load could be carried by the bar. 


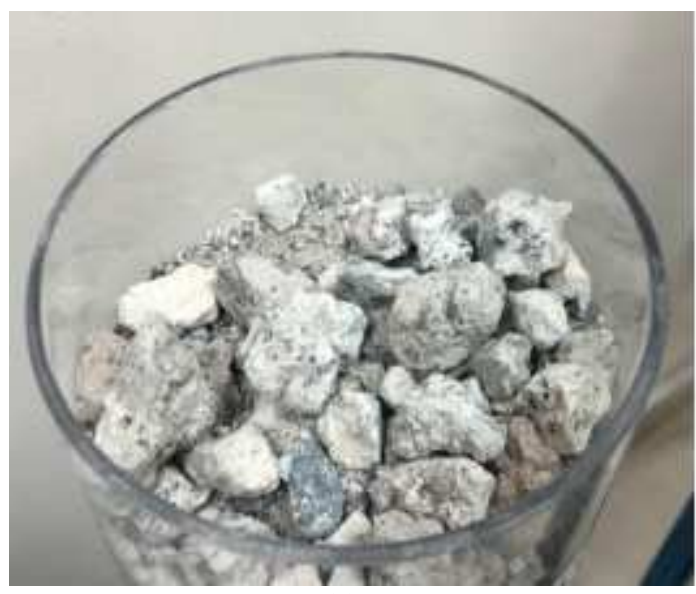

(a)

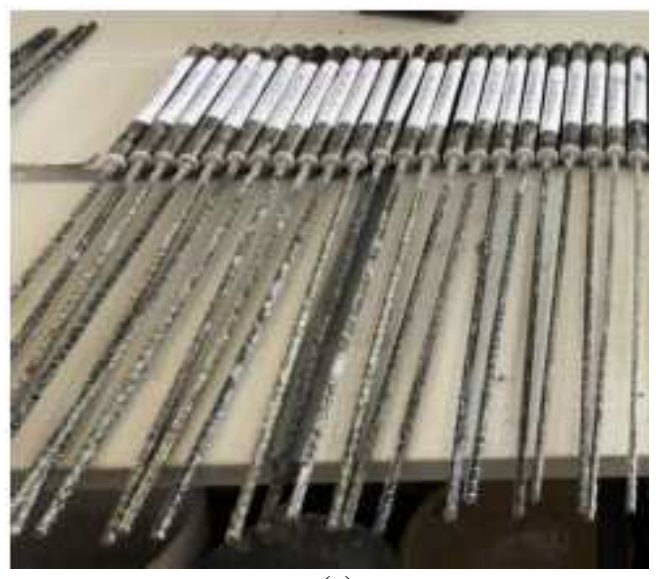

(c)

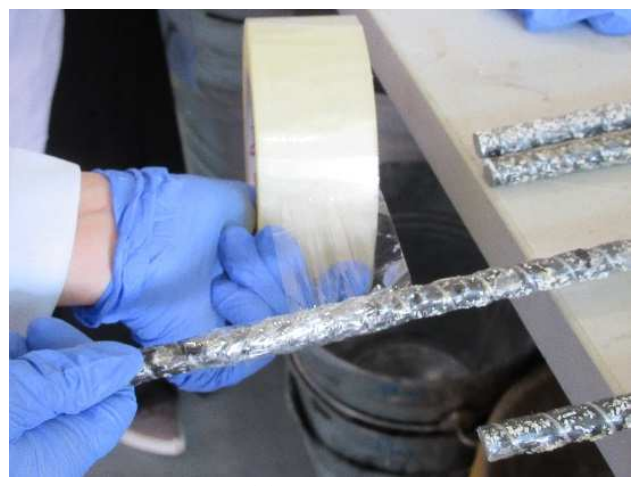

(e)

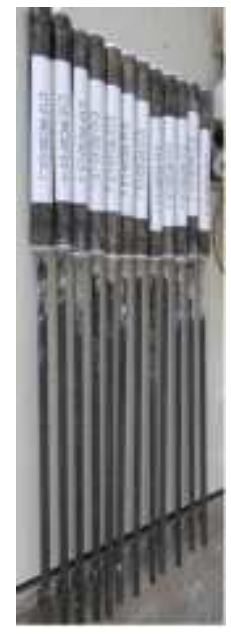

(b)

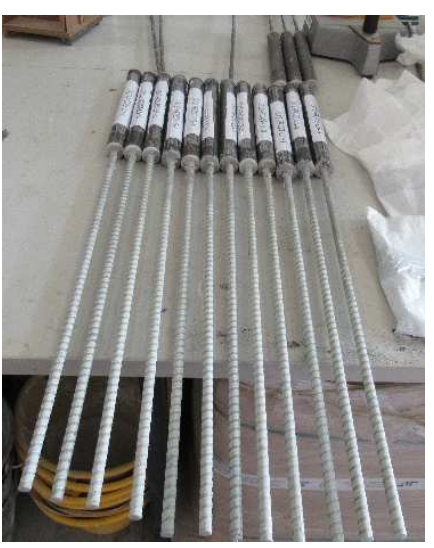

(d)

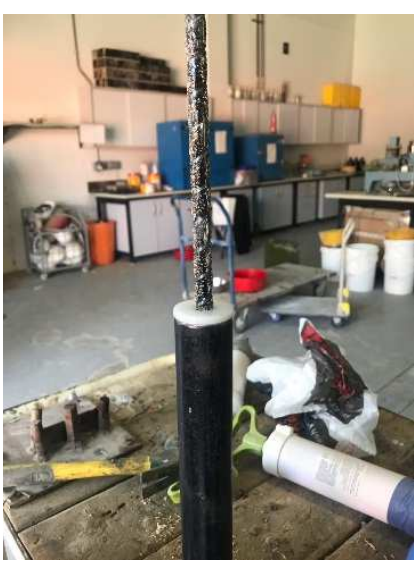

(f) 


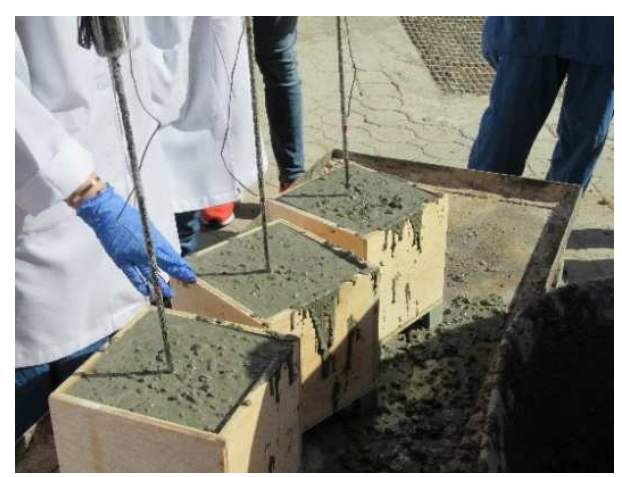

(g)

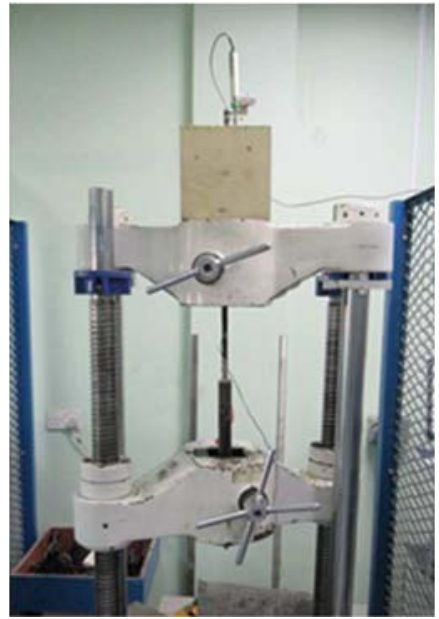

(i)

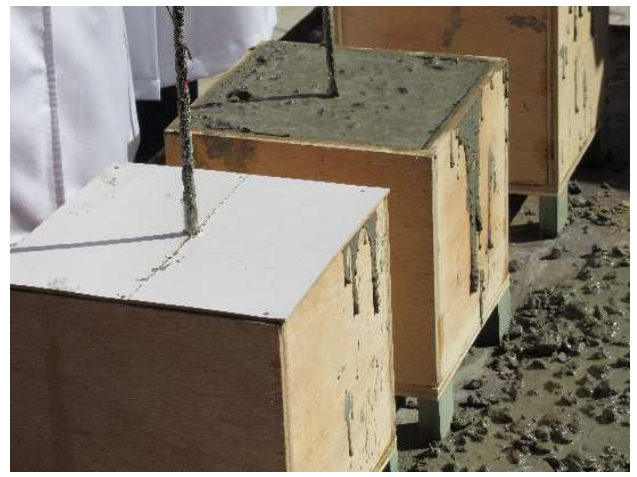

(h)

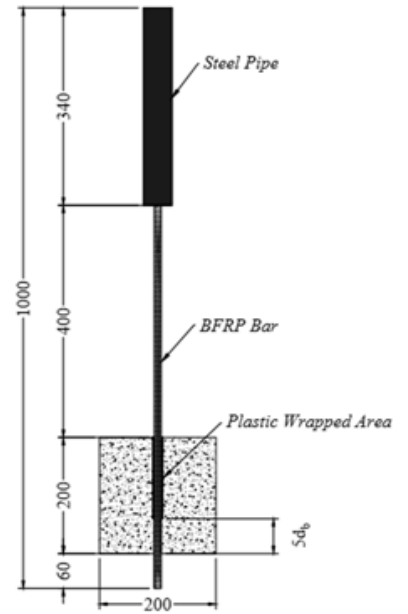

(j)

Fig. 1. Bond slip test: (a) recycled aggregates; (b) CFRP bars; (c) BFRP bars; (d) GFRP bars; (e) plastic taping of the FRP bar; (f) FRP bar in steel pipes; (g) concrete casting in wooden moulds; (h) adjusting the verticality of FRP bars; (i) test setup; (j) geometry of test setup.

\section{Experimental results}

This section presents the experimental results in terms of bond load-slip relations, maximum bond load and failure modes. The results are analysed based on the influence of the concrete strength, types of concrete, and the type of the FRP bar. The slip is considered to be the difference in displacement between the concrete and the FRP bar in the direction opposite to the applied load, which is taken directly from the LVDT's readings. Table 1 presents the maximum bond load along with the failure modes for the tested specimens.

\subsection{Bond load-slip relations}

Representative curves for the investigated specimens are shown in Figs. 2 (a-c) to illustrate the bond load-slip relations obtained for the different specimens BFRP, GFRP and CFRP bars, respectively. The figures show the slip at the unloaded end opposite to the applied load. In specimen B12-RC45, the slip was not fully recorded due to the sudden layover of the LVDT. In each figure, the curve of the 12-mm bar diameter in the regular-aggregate concrete is shown for the sake of comparison.

The overall behaviour of the curves is characterized by an initial increase in the bond load with little slip, which is known as the micro-slip stage. In this stage, the pull-out between the 
bar and the surrounding concrete is initiated and the load is transferred towards the unloaded end. Once the maximum load has been attained, the load remains almost constant for any further increase in slip. The constant bond load with the continuous increase of slip is attributed to the high bearing and friction between the FRP bars and concrete.

Figure 2(a) shows the bond force-slip relationships obtained for specimens B12-RC30, B12-NC30, B12-RC45 and B12-RC60. These specimens have different concrete strengths and types of concrete (recycled-aggregate concrete and normal-aggregate concrete). The figure shows that similar curves are obtained for the specimens with natural and recycled-aggregate concrete for the same concrete strength (30 MPa). The two specimens showed similar stiffness behaviour in the early phase of the test. However, the slip of the recycled aggregate specimens is higher than the one with normal aggregate. This indicates that the use of the recycled aggregate enhances the bearing friction between the BFRP bars and concrete. In the recycled aggregate specimen, the descending branch fluctuates and becomes almost plastic when the maximum load is attained. For specimens B12-RC45 and B12-RC60, as the concrete strength increases, so does the bond load. There is no slip recorded for specimen B12-RC45 after reaching the maximum load, as shown in Fig. 2(a). This occurred because this specimen experienced concrete splitting when the maximum bond load was attained. The descending branch of specimen B12-RC60 was captured although the failure mode was concrete splitting.

Figure 2(b) shows the bond force-slip relationships for specimens with GFRP bars. The curves show that no appreciable differences are observed in the bond load-slip relations from the ones with BFRP bars. This indicates that GFRP and BFRP bars have similar bond mechanisms. Therefore, the BFRP bars can replace the GFRP ones since the bond development and deterioration are similar. It can be observed from Fig. 2(b) that the type of aggregate and concrete strength have no effect on the initial stiffness of the bond force-slip curves because the initial stiffness of all the curves is almost identical. It should be added that although surface treatments of BFRP (sand-coated) and GFRP (ribbed) bars are different, no difference in the post-peak behaviour of the two types of bars is accounted for. The fluctuating post-peak behaviour observed in the BFRP and GFRP bars can be attributed to the wedging action, which is a consequence of a confinement action exerted by the surrounding concrete on the FRP bar and which increases the bearing resistance of the bond mechanism [8].

Figure 2(c) shows the bond load-slip relation for specimens C12-RC30, C12-NC30, C12$\mathrm{RC} 45$ and $\mathrm{C} 12-\mathrm{RC} 60$. The figure indicates that for the recycled-aggregate concrete, although the bond force is similar to the ones with BFRP and GFRP bars, the slips corresponding to the maximum bond load $(0.006 \mathrm{~mm})$ and at failure $(0.04 \mathrm{~mm})$ are smaller compared to the ones recorded for the other types of FRP bars. The phenomena can be attributed to the failure mode observed in all CFRP bar specimens, which is bar pull-out failure regardless of the change in the recycled-aggregate concrete's strength, as shown in Table 3. The values of slip at the maximum bond load $(0.02 \mathrm{~mm})$ and at failure $(0.15 \mathrm{~mm})$ are higher in the regularaggregate concrete compared to the ones in the recycled-aggregate concrete. Sometimes the descending branch is short because failure occurred immediately after the descent began.

\subsection{Bond failure modes}

A summary of failure modes observed during the pull-out tests is provided in Table 3 . The experimental results demonstrate that the concrete strength has a significant influence on the failure mode. This result is different from the one obtained by Baena et al. [2] who mentioned that failure mode for FRP bars is dependent on the surface treatment and no concern should be given to the concrete grade. 


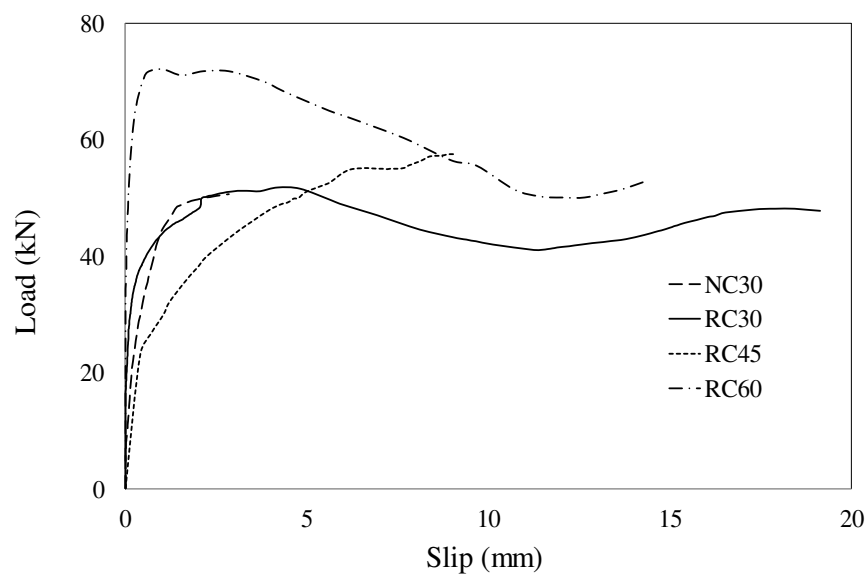

(a)

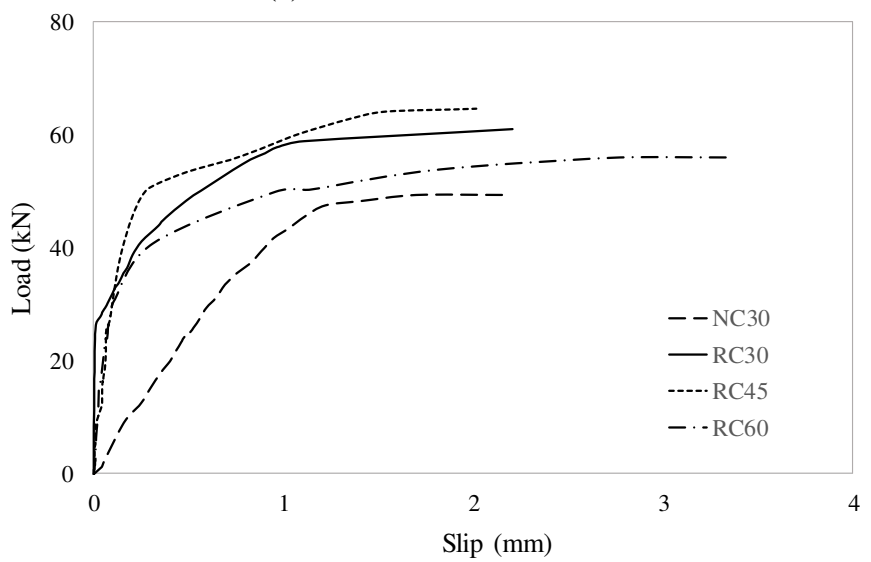

(b)

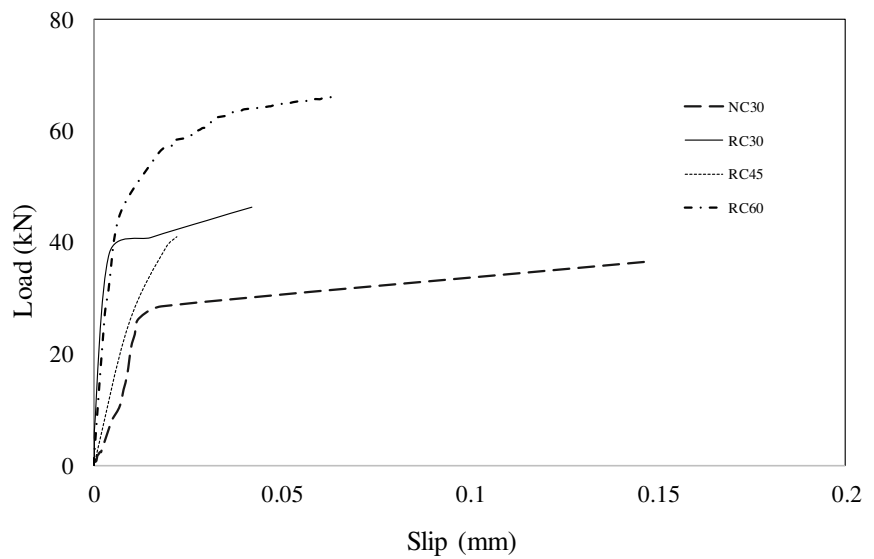

(c)

Fig. 2. Bond load-slip relations: (a) BFRP bars; (b) GFRP bars, and (c) CFRP bars

All specimens with $30 \mathrm{MPa}$ concrete strength failed in pull-out failure with no cracks observed at the surface of the concrete block after failure, as depicted in Fig. 3. Visual inspection shows low damage to the surface of the BFRP and GFRP bars regardless of their 
surface treatment, as provided in Figs (a) and (b) respectively. In addition, no concrete particles attached to the FRP bars are present after failure. It ought to be noted that the failure was governed by the shear strength interface at the FRP bar layers rather than the interface between the FRP bar and the concrete. Furthermore, the incomplete peeling off of the bar's outer surface explains the fluctuating bond load-slip behaviour where the residual outer surface resulted in resisting the pull-out load applied. For CFRP bars, it can be noticed that the bar's outer surface was peeled off along the location of contact between the bar and concrete at all concrete strengths. At the direction of the unloaded end, the bar's outer surface showed no apparent damage.

For the BFRP bars in 45 and $60 \mathrm{MPa}$ as well as GFRP bars in $60 \mathrm{MPa}$, the concrete splitting is the dominant failure mode where the concrete block is separated into two pieces at the location of the FRP bar, as shown in Fig. 3(d). The failure was brittle with no advance warning of crack on the concrete block side surfaces. The concrete splitting failure indicates the proper bond between the bars and the concrete, which prevents the occurrence of the pullout failure. In some cases, the BFRP bars were still attached to the concrete after the splitting failure mode (Fig. 4c). These results are identical to the ones observed for the pull-out bond behavior in normal concrete [9-11].

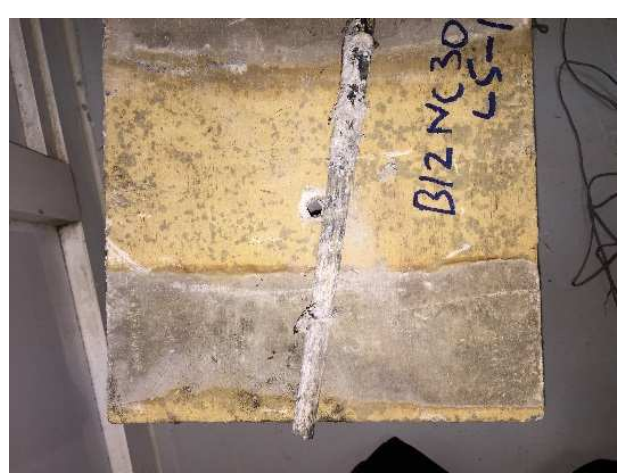

(a)

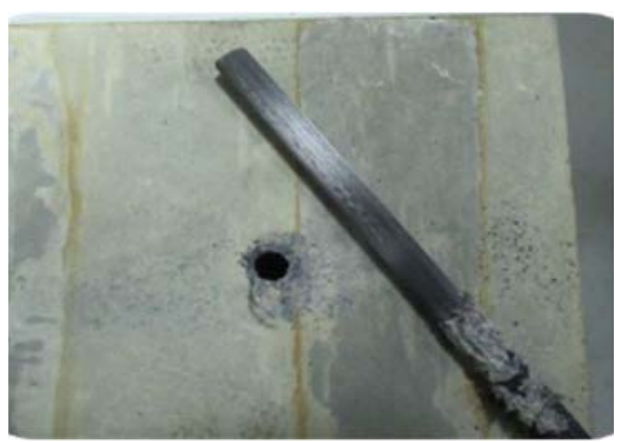

(c)

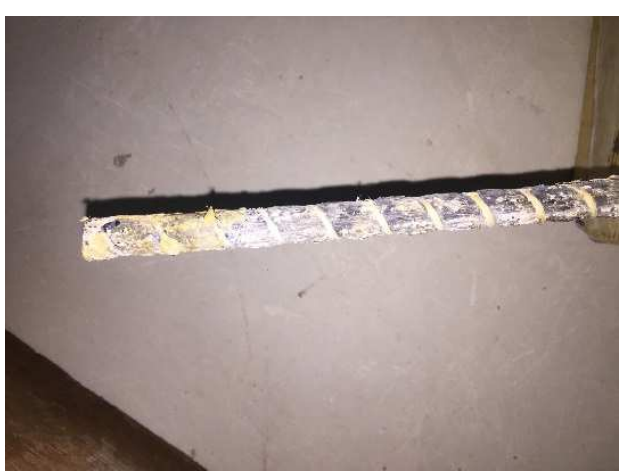

(b)

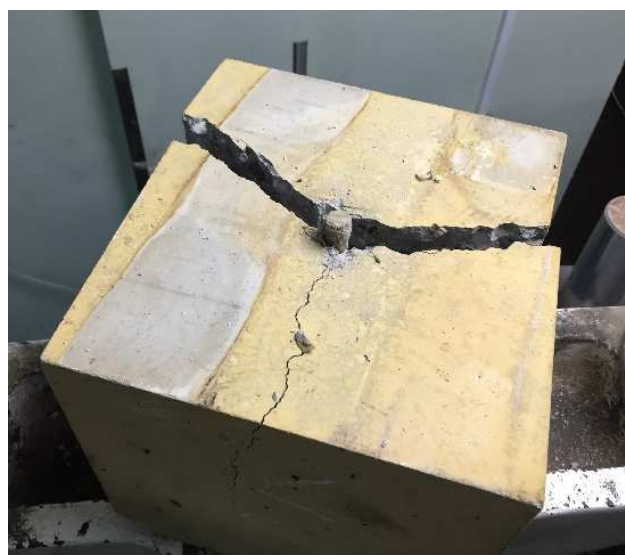

(d)

Fig. 3. Bond failure modes: (a) pull-out failure of BFRP bars; (b) BFRP bar after pull-out failure; (c) pull-out failure of CFRP bar, and (d) concrete splitting failure 


\section{Conclusions}

An experimental investigation was carried out with the objective of understanding the bond mechanisms of CFRP, GFRP and BFRP bars in the recycled-aggregate concrete. To this end, various grades of concrete strengths were investigated. The bond behaviour of the FRP bars in the regular-aggregate concrete was carried out for the sake of comparison. Based on the results of this study, the following conclusions can be drawn:

- In general, the type of aggregate used (normal or recycled) has no influence on the pullout bond behaviour of FRP bars. The initial stiffness, maximum bond load and descending branch were identical for the recycled-aggregate and natural aggregate concrete;

- An increase in bond load and a change in the failure mode are observed with the increase of the concrete strength for BFRP and GFRP bars;

- The peeling off of the outer surface of CFRP bars at pull-out failure cannot be avoided by providing high concrete strength;

- The use of the recycled aggregate for BFRP and GFRP bars enlarges the slip and corresponds to failure and delay in the occurrence of pull-out failure.

\section{References}

1. T.R. Sonawane, S.S., Pimplikar. Use of recycled aggregate concrete, Second International Conference on Emerging Trends in engineering (ICETET-09), Nagpur, Maharashtra, India, (2009).

2. M. Baena, L. Torres, A. Turon, M. Llorens, C. Barris, Bond behaviour between recycled aggregate concrete and glass fibre reinforced polymer bars, Constr. Build. Mater. 106, (2016).

3. H. Liu, J. Yang, X. Wang, Bond behavior between BFRP bars and recycled aggregate concrete reinforced with basalt fiber, Constr. Build. Mater. 135, (2017).

4. ACI E1-16. Aggregate for Concrete, American Concrete Institute, ACI committee E701, Farmington Hills, USA, (2016).

5. BS 8500. Complementary British Standard to BS EN206, Part 1-Methods of specifying and Guidance for the Specifier, London, UK, (2015).

6. PCA. High-Performance Concrete, Design and Control of Concrete Mixtures, $16^{\text {th }}$ Edition, Washington, USA, (2016).

7. ASTM standard D7913/D7913M, Bond Strength of Fiber-Reinforced Polymer Matrix Composite Bars to Concrete by Pullout Testing, West Conshohocken, PA, (2014).

8. Z. Achillides, K. Pilakoutas, Bond behavior of fiber reinforced polymer bars under direct pullout conditions, J. Compos. Constr. 8, 2, 173-181, (2004).

9. F. Elgabbas, P. Vincent, E.A. Ahmed, B. Benmokrane, Experimental testing of basalt-fiberreinforced polymer bars in concrete beams, Composites: Part B 91, 205-218, (2016).

10. M. Hassan, B. Benmokrane, A. Elsafty, A. Fam, Bond durability of basalt-fiberreinforced (BFRP) bars embedded in concrete in aggressive environments, Composites: Part B 106, 262-272, (2016).

11. C. High, H.M. Seliem, S.H. Rizkallal, Use of basalt fibers for concrete structures, Constr. Build. Mater. 96, 37-46, (2015). 